\title{
Marketing mix on Case Study Business Kini Cheese Tea Seturan at Yogyakarta
}

\author{
Fitri Indira Hapsari, Sutrisno
}

\begin{abstract}
Cheese Tea drinks, one of which is Kini Cheese Tea, becoming a trend among young people, becomes one of the opportunities to run a business in the culinary field. This research aims to analyze the strategy and business innovation of Kini Cheese Tea in Seturan Yogyakarta. The method used in this study is a case study. Data collection techniques used are observation, interview, and documentation studies. The results showed that 1) after conducting some analysis in terms of marketing, there are vast opportunities because the products marketed are unique and reasonably priced in all segments in Yogyakarta, 2) to analyze the company's competitiveness to consumers and other competitors can be used porter five forces analysis, and 3) early promotion will be very helpful in introducing a company at the beginning of its establishment.
\end{abstract}

Index Terms-Kini Cheese Tea, Business Plan, Franchise, Marketing.

\section{INTRODUCTION}

In this modern era, more and more culinary businesses are popping up in the market. It can be characterized by the number of restaurants, cafés, and various food and beverage stand that appear with their characteristics. The development of the culinary food business also makes culinary drinks in Indonesia increasingly have many fans. For example, one of the drinks currently a trend that is a drink with a mixture of cream cheese as the main topping, innovation opportunities such beverage business is considered quite interesting to run, because considering for this kind of drink has many fans in the middle of the existing market. Furthermore, culinary snack drinks are increasingly in demand by consumers, and their good taste makes consumers more curious about the taste of a drink. After analyzing consumer tastes, the trend favored by consumers is milk-type beverages that are innovated with certain ingredients. Then the cheese tea beverage business can be said to fit consumers' tastes and is believed to provide a hefty profit.

Yogyakarta, a student city, will be an excellent opportunity to sell and open a cheese tea stand at an affordable selling price for existing students and students. Some cheese tea beverage products have started to spread in the city of Yogyakarta and its franchise business. Businesses with franchise systems are essentially a method of distributing goods and services to consumers. The development of the food and beverage franchise business is relatively rapid

Fitri Indira Hapsari, Master of Management Study Program, Faculty of Business And Economics, Islamic University of Indonesia, Yogyakarta, Indonesia

Sutrisno, Master of Management Study Program, Faculty of Business And Economics, Islamic University of Indonesia, Yogyakarta, Indonesia, nowadays, significantly because many food businesses have been growing and advancing, then diverting it to franchises. The number of cheese tea beverage franchises with different menus and variants and the price of various products makes the franchise business a business idea that should be taken into account.

A franchise business can be a solution in starting a new business with the advantage of branding products already known before by the existing market. Furthermore, this business plan will use the business concept by using franchises from cheese tea brands well-known in the national culinary market.

Milineal generation has opportunities and opportunities to be independent in financial one of them passes through a business with a franchise management system. It is because a franchise business provides convenience for businesses to run it. Sales systems and marketing strategies are already systemized on the franchise. The franchise is a contractual relationship that occurs between producers, service organizations, wholesalers, and independent business people who buy rights and use them to operate than one or more in the franchise system [1]. For the cheese tea market condition before the entry of Cheese Tea, the consumers mostly still pay a lot to buy a cheese tea drink. The presence of cheese tea products from Kini Cheese Tea can solve the solution for consumers which they object to the market price of cheese tea that tends to be expensive. Whereas now students and the public to the lower middle class can consume it without thinking about the price.

This business was chosen and run as the final task, and because the increasing number of cheese tea drinks that enter Indonesia, especially in Yogyakarta, makes people more consumptive to snacks on this one drink. Therefore, the franchise Cheese Tea is now chosen to be a business that can provide opportunities in the future. In addition, Cheese Tea now has an easy franchise concept, and the capital issued is very affordable, and the purchase of raw materials can be easily obtained in bakeries. Then for the businessman who wants to join this franchise, only in the burden of paying fees at the beginning of purchasing booths and raw materials without sharing profits in the future. Another convenience is the freedom to choose raw materials elsewhere. The current concept of the Cheese Tea franchise provides opportunities for business people who join to innovate to increase sales.

Kini Cheese Tea allows following the trend of snack drinks in the future. However, the many trends of cheese tea drinks popping up today can provide a minor obstacle in maintaining customers. From these constraints, Cheese Tea now has to prepare particular strategies to be able to compete. The raw 
materials used have good taste quality and prices that tend to be cheap, but it is not sure that the price is still valid for the future. So it is feared that when the price of raw materials rises and the price of beverages rises to cause consumers can turn to other brand products. Therefore, the plan is to introduce the Kini Cheese Tea product among students and the community to make this beverage business one of the cheese tea drinks more affordable than others. With the advantages that will be used to develop and create a variety of new menus where the new menu we adjust to the interests of the time.

This study aims to analyze the strategy and business innovation of Kini Cheese Tea in Seturan Yogyakarta.

\section{LITERATURE REVIEW}

\section{A. Marketing Management}

Marketing Management is one of the main activities carried out by the company in maintaining the continuity of its company to continue to grow and earn profit. According to Kotler and Armstrong, marketing management is an art and science in choosing market goals and building profitable relationships, where marketing management is also defined as customer management and demand management [2].

Another opinion suggests that marketing management is an activity in analyzing, planning, implementing, and controlling programs that are compiled in the formation, development, and maintenance of profits from exchange activities or transactions through target markets aimed at achieving the goals of an organization in the long run [3].

\section{B. Strategy Management}

Wheelen and Hunger argue that its strategy is a comprehensive plan of achieving its mission and goals. As a result, the strategy maximizes competitive advantage and minimizes the limitations of competing [4].

\section{Human Resource Management}

Human resource management is a science that learns how to empower employees in a company, make a structure of work, develop the capabilities of existing employees, and identify an approach in developing employee performance and reward the work they do [5].

HR involvement is essential to the success of the organization change process because HR is an important subject that will implement the change process of the results and process of planned changes [6].

\section{Operational Management}

According to Heizer, Operations management is a series of activities carried out by the company in producing valuable goods and services by converting an input into output. Operational management, in general, plays a role in strategic issues in determining production plans (manufacturing) and project management methods as well as the implementation of information technology network structures [7].

\section{E. Financial Management}

According to Brigham \& Houston, financial management aims to get maximum profit, minimize existing risks, supervise the flow of funds so that the use and search can be known, and maintain the company's flexibility. Therefore, financial management is planning, budgeting, inspection, management, control, search, and storage of funds owned by a company to obtain the cheapest source of capital and use as effectively, as productively as possible to generate profit [8].

\section{METHOD}

The report uses qualitative methods with case study models - data collection techniques using observation, interview, and documentation studies. The report's subject is the Kini Cheese Tea franchise located in Seturan adjacent to UPN Universitas Pembangunan and YKPN.

Kini Cheese Tea is a franchise with the concept where the franchisee actors only buy the trademark and make payment of franchise fees at the beginning of the agreement where the price of the business package sold consists of 3 forms of business packages with different prices, and packages include a mini booth for sale. The amount and period of the initial payment are stated in the agreement. Of the three package options available, due to the price comparison of some existing packages where the package differences are located only in different booth forms, the Business Plan is executed using the economic business package now 3 to save initially. costs and maximize revenue.

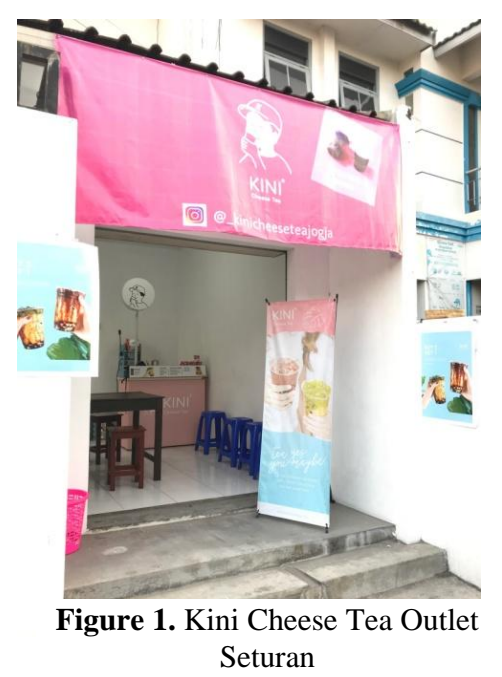

\section{RESULTS AND DISCUSSION}

\section{A. Business Feasibility Assessment Kini Cheese Tea Seturan}

1. Payback Period (PBP)

In the calculation PBP that is for 11 months four days if compared to the economic age for five years, it can be concluded that the investment should be accepted because BP is faster than its economic life.

\section{Net Present Value and Profitability Index}

The interest rate is assumed to be $15 \%$. Based on the Theory of Business Feasibility Study, if PV of Proceeds is more significant than PV of Out Lays, Rp. 536.861.308,- so NPV is a positive value, then the effort is worth to be implemented.

Based on the results of the following count, if the PI is more significant than one, then the proposal is accepted. On the other hand, if the PI is smaller than one, then the proposal is rejected. Based on the calculation result, the Profitability 
Index (PI) is 12.00, then the proposed investment is accepted.

3. Internal Rate of Return

Based on the calculation of the IPP's amount of $47.29 \%$ and the required rate of return of $15 \%$, then the proposed investment is accepted.

4. Average Rate Return (ARR)

$\mathrm{ARR}=($ Average EAT / Average Investment $) \times 100 \%$ $=(\operatorname{Rp} 878.940 .000 / 5) / \operatorname{Rp} 11.313 .320) \times 100 \%$ $=155,54 \%$

\section{B. Realization of Marketing Aspects}

After planning the marketing aspect, the next step is to do a marketing plan prepared by Kini Cheese Tea is introducing its products where the composition of the plan is as follows:

1. The initial creation of the social media accounts Kini Cheese Tea.

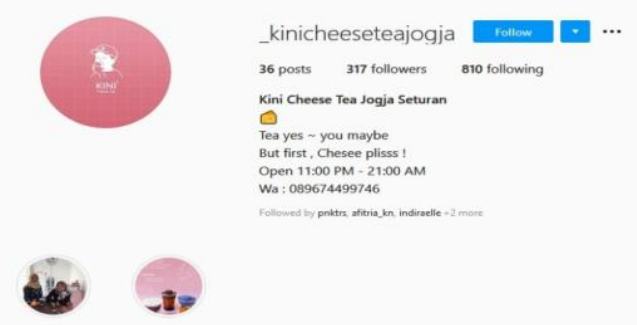

Figure 2. Kini Cheese Tea Seturan's Instagram

2. Using promotional services and also to review the quality of flavors of Kini Cheese Tea. With it, consumers will be easy to explore with the products reviewed.
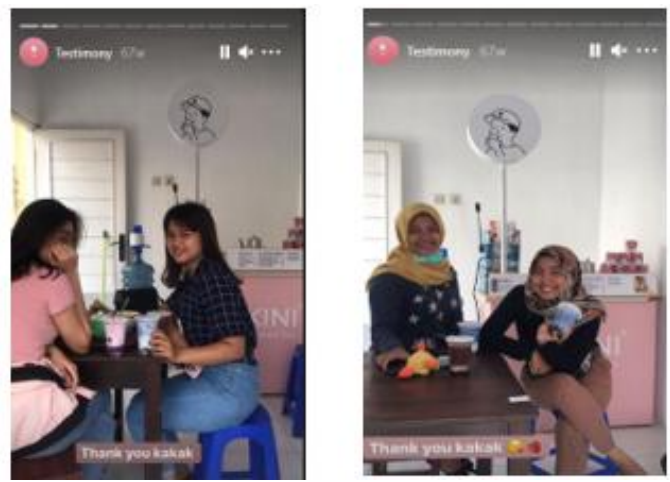

Figure 3. Consumers reviews

3. Put up a banner Kini Cheese Tea is quite visible on the roadside to make it easier for consumers or the target market to see outlets.

4. For sales strategy, promos will be conducted with different promo forms in a certain period, such as giving discounts or conditional free promos such as "buy two get one free" for every second purchase.

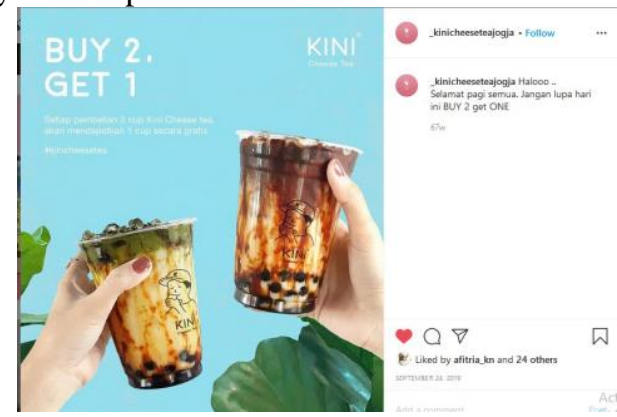

Figure 4. Kini Cheese Tea Seturan's Promo
In the sales period of March 2020-March 2021, there was a Covid Pandemic where the government simultaneously imposed restrictions on operating hours on all public facilities such as tourist attractions, shopping centers, including beverage outlets. The aftermath of the pandemic affected the number of customers, and they chose not to travel and do their activities at home. Several marketing strategies are carried out in such situations by presenting several diverse promo menus in cooperation with Grabfood services.

\section{Comparison of Marketing Planning and Realization}

The marketing planning planned forKiniCheese Tea went well; however, it requires additional costs to support product marketing, that is, to hire a celebrity service to review the taste of the drink Kini Cheese Tea raw materials used for the means of promotion buy 2 get 1 .

Sales Kini Cheese Tea which initially focused on customers dating to outlets, now switch to grabfood sales due to the Covid19 pandemic outbreak, makes Cheese Tea Now create innovation for the strategy in its sales by targeting consumers who want to buy Cheese Tea now from home. Working with Grabfood drinks, Kini Cheese Tea can be ordered easily for the customers at home makes sales of Cheese Tea Now better despite the pandemic.

With the initial switch, all customers can sit by enjoying drinks Kini Cheese Tea in outlets now have to order drinks with taking away system or online, impacting the reduction of dine-in. As a result, visitors significantly reduced by more than $30 \%$ from the target of early visitors in March 2020, where at the beginning of the plan, visitors reduced to 20 people. However, the number of visitors gradually increases every month due to changes in sales and marketing strategies made online.

\section{Aspects of Human Resources ( HR)}

Running Kini Cheese Tea consisting of 2 employees guard outlets with the outlet operational schedule from 11.00-21.00 goes well. For the holiday schedule made alternately from Monday to Saturday, with sesame outlet guard team. For cashiers, Cheese Tea now uses the cashier application machine " SPOTS," which is a multifunctional device with a mobile-based POS system to help cashier transactions that have been integrated with OVO to provide options for customers to pay using debit or credit card and reduce the amount of cash. The SPOTS app gives some benefits, including monitoring revenue and getting daily reports sent by e-mail. Indeed this can facilitate cashier activities in managing daily operational money. In addition, with the spots application, the owner can directly see the outlet sales report.

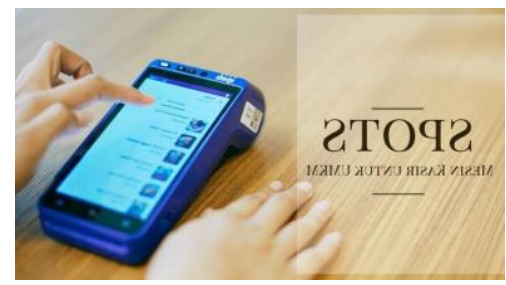

Figure 5. SPOTS 


\section{E. Realization of Operational Aspects}

For the realization of operational aspects of Kini Cheese Tea, divided into ten strategic decisions of operations management are as follows:

1. Design of Goods and Services. In this stage, Kini Cheese Tea is the cheapest cheese tea drink with a strategic location and with the concept of taking away or sit back and relax in the outlet. Products offered by Kini Cheese Tea is the concept of cheese tea with a variety of flavor options that have been provided and topping cream cheese on it. The raw materials to be used are prepared in advance before the outlet is opened. Boba, cream cheese, and milk tea have been cooked in advance by the outlet guard where when there are consumers who are dating to buy Cheese Tea. The outlet guard does not have difficulty compounding the ordered beverages.

2. Determination of Quality. For the quality standards of products on The first Cheese Tea now for powder used is a powder with premium quality from Toffico to maintain taste quality.

3. Process and Capacity Design. On the design of processes and capacities related to quality, human resources, supplies, scheduling, and maintenance carried out after completion of the design of goods and services.

4. Location Selection. The selection of Kini Cheese Tea location has been adjusted to the location near the student settlement and in the middle of a densely populated area. Cheese Tea Is also close to several large campuses such as FE UII, UPN Veteran Yogyakarta and STIE YKPN. The location is located on Jalan Puluhdadi Seturan, Yogyakarta. Around the business site, there are many houses and boarding houses and students, and is a

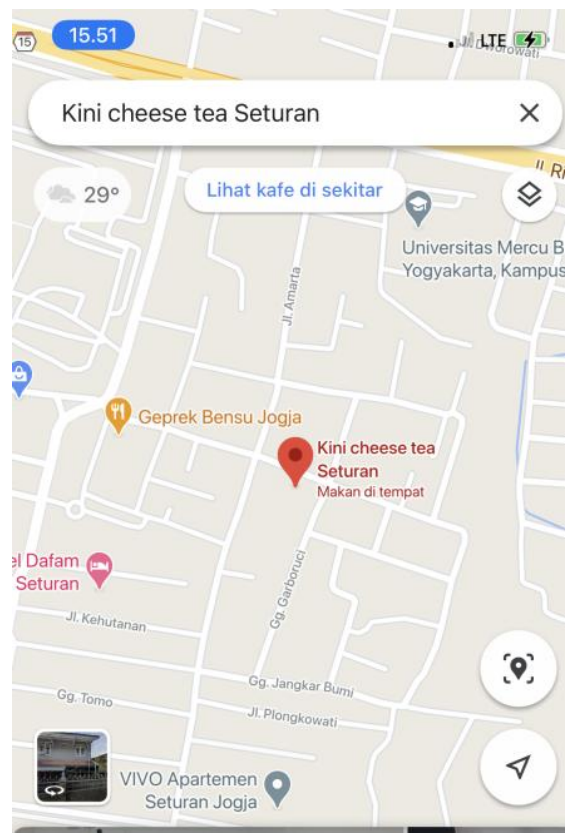

Figure 6. Kini Cheese Tea Seturan's Google Map

road that leads to the UPN campus.

5. Layout Design. For the layout of raw materials Kini Cheese Tea, a) storage of flavoring powder and raw materials and b) serving area after finishing area.
6. HR Strategy in Cheese Tea Now. For HR strategy in managing the workforce and managing the work effectively and efficiently, sop is prepared the outlet guard must apply that in order to improve the quality of service with as follows:

7. Supplies. In this stage, for the supply of raw materials Now Cheese Tea will be made, ordering once a month, such as raw materials and creamers and other processed materials. Supplies such as gallons, ice cubes, orders are made regularly according to the stock runs out, usually every day or every three days.

8. Maintenance. The maintenance strategy applied by Kini Cheese Tea to maintain the quality is done by the owner and the outlet's guard. For the operational process, the number of sales and cashiers is monitored directly by the owner through the SPOT cashier application, which shows the daily sales, the number of menus sold, and the revenue every day.

\section{F. Financial Aspects}

Referring to the planning of the financial aspects made to the financial aspect plan, the list of assets and the initial capital divestment plan is the same, and there is no change from the original plan. However, during the current period from October 2019 to September 2020, there was a decrease in visitors due to the Covid-19 Pandemic. Furthermore, the following financial statements that have been running during the period of business practices In the current period in the first two months of December and January, which is the initial introduction stage to prospective customers about the drink Kini Cheese Tea as a new beverage outlet stands so that for the target consumers who want still not achieved. However, in the 2nd month, the following month, there was an increase and exceeded the desired sales target.

Precisely in March 2020, the Covid-19 Pandemic that occurred has a significant impact on all world economic activities, especially in the culinary market. The decrease in revenue occurred due to government policy to limit all community activities such as travel ban, lockdown, closure of tourist attractions, and restrictions on operating hours of public facilities and restaurants. The impact of the pandemic resulted in many consumers choosing to do activities from home. Cheese Tea's sales and marketing strategy that focuses on sales at outlets are now more focused on online sales or through the Grab and Gojek apps. For operations before the pandemic, the customers buy cheese tea and enjoy while sitting in the outlet turned into a takeaway system because the seats available in the outlet in the less to maintain health protocol in pandemic Covid. After innovation, income began to gradually improve and get better from month to month, considering the health protocol has also started to become the obligation and awareness of each individual. As a result, consumers who come to outlets Kini Cheese Tea has started to increase, and online sales remain well balanced. 


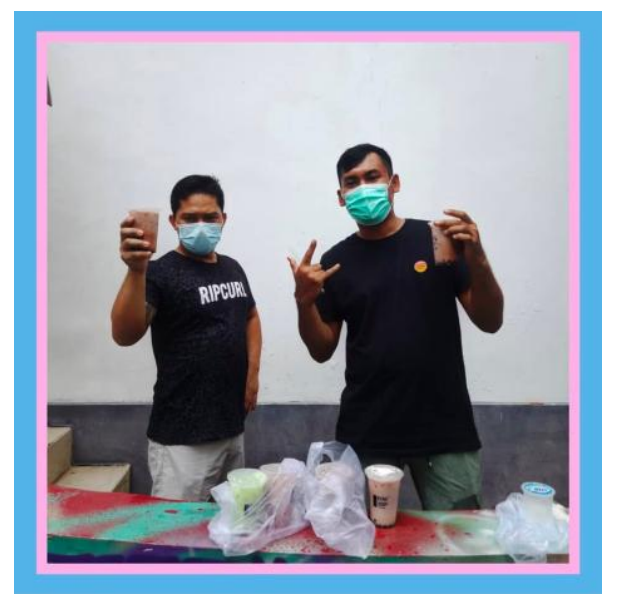

Figure 7. Covid-19 Health Protocols of Kini Cheese Tea Seturan

\section{G. Business Evaluation}

1. In marketing, several changes in strategy in promoting Kini Cheese Tea were previously targeted promotions to produce sales targets consumers who come and order Kini Cheese Tea in the Outlets such as BUY 1 GET 1. However, now experiencing changes where marketing focuses directly on consumers and online consumers through gofood or grabfood services.

2. In the aspect of strategy where previously using a cost-leadership strategy for the menu without topping cream cheese can be an alternative for consumers who want a menu of drinks at a low price.

3. For operational aspects, changes in outlet operating hours and the addition of SOP as a form of participation in fighting the Covid-19 Pandemic.

4. For the financial aspect, the comparison in the plan and realization has been running optimally before the Covid-19 Pandemic outbreak.

\section{H. Business Development Plan}

Furthermore, this business's development and progress plan will be done by creating a new variant menu in a certain period and opening several new branches in other cities, one of which is Klaten City, with a broader target market that targets students also all existing segments. Follow up on the changes in conditions that occur today as a result of the COVID-19 pandemic, where outlets Kini Cheese Tea can do a good adjusting and can get used to the new normal era, Kini Cheese Tea will perform services following the standards with strict Health Protocol Procedures for all employees and visitors.

Some form of SOP concerning health protocol that the government has recommended, where Cheese Tea now appeals to every customer who comes to the outlet Kini Cheese Tea, always wears a mask before entering the outlet. Customers are advised to wash their hands first that has been provided in front of the entrance. For employees are always obliged to wear a mask and also poke their hands every time doing service. Then for the strategy on the sale of Cheese Tea now and promotion emphasized simultaneously, i.e., offline and online where for the concept of sales and promotion will be done by creating several new variant menus tailored to the interests of the public at that time. The promotional strategy will always be done on the Instagram account Kini Cheese Tea which will be done some free menu, and customers can freely select the menu to increase customer satisfaction.

\section{CONCLUSION}

After some analysis in terms of marketing, there are vast opportunities because the products marketed are unique, and the price is quite affordable in all segments in Yogyakarta. Therefore, SWOT analysis is essential to know the potential that can be achieved, know some weaknesses and shortcomings, minimize risk at Cheese Tea Now, and explore the desired business opportunities. Furthermore, business canvas model analysis is equipped with the concept of Flower of Service in arranging essential points in creating a business that not only sells a product but also creates innovations in the franchise business and creates a promotional system that can increase the value of the quality of outlets Kini Cheese Tea.

\section{REFERENCES}

[1] Kotler, P; Armstrong, G., "Marketing Principles", Vol. 1, Erlangga, Jakarta, 2008.

[2] Kotler, P., and Amstrong, G., "Principles of Marketing”, 15th Global Edition, Pearson, 2018.

[3] Hunger, D.J., and Wheelen, L. T, "Strategic Management and Business Policy", (13th Edition), Pearson, United States of America, 2012.

[4] Assauri, S., "Marketing Management", Rajawali Press, Jakarta, 2013.

[5] Bohlander, G, and Snell, S., "Principles of Human Resources. Management", 2010.

[6] Moran, J W., and Brightman, B. K., "Leading Organizational Change", Journal of Workplace Learning, 12 (2):66-74, 2000.

[7] Heizer, J., and Render, B., “ Operations Management”, issue 11, Salemba Empat, Jakarta, 2017.

[8] Brigham, E. F., and Joel F. H.," Financial Management Basics ”. Book 1, Issue 11, Salemba Empat, Jakarta, 2014. 